\title{
Magnetron Deposition of Metal-Ceramic Protective Coatings on Glasses of Windows of Space Vehicles
}

\author{
Victor P. Sergeev ${ }^{1,2, a)}$, Victor E. Panin ${ }^{1,2, b)}$, Sergei G. Psakhie ${ }^{1,2, c)}$, \\ Alexandr G. Chernyavskii ${ }^{3, \text { d) }}$, Valerii P. Svechkin ${ }^{3}$, Yurii F. Khristenko ${ }^{4}$, \\ Mark P. Kalashnikov ${ }^{1,2, e)}$, and Andrei V. Voronov ${ }^{1, f)}$ \\ ${ }^{1}$ Institute of Strength Physics and Materials Science SB RAS, Tomsk, 634055, Russia \\ ${ }^{2}$ National Research Tomsk Polytechnic University, Tomsk, 634050, Russia \\ ${ }^{3}$ Russian Cosmic Corporation "Energy", Korolev, 141070, Russia \\ ${ }^{4}$ Scientific Research Institute of Applied Mathematics and Mechanics of Tomsk State University, \\ Tomsk, 634050, Russia \\ a) Corresponding author: vserg@mail.tomsknet.ru \\ b) paninve@ispms.tsc.ru \\ c) sp@ms.tsc.ru \\ d) cherniav@space.ru \\ e) kmp1980@mail.ru \\ f) avor@sibmail.com
}

\begin{abstract}
Transparent refractory metal-ceramic nanocomposite coatings with a high coefficient of elastic recovery and microhardness on the basis of $\mathrm{Ni} / \mathrm{Si}-\mathrm{Al}-\mathrm{N}$ are formed on a glass substrate by the pulse magnetron deposition method. The structure-phase states were investigated by TEM, SEM. It was established that the first layer consists of Ni nanograins with a fcc crystalline lattice, the second layer is two-phase: 5-10 nm nanocrystallites of the AlN phase with the hep crystalline lattice in amorphous matrix of the $\mathrm{Si}_{3} \mathrm{~N}_{4}$ phase.
\end{abstract}

Keywords: magnetron deposition, protective coating, glass, space vehicle, structure-phase state, microhardness, crater density

\section{INTRODUCTION}

Continuous bombardment of the illuminator glasses of a spacecraft by high-velocity micrometeoroids leads to the formation of craters and then microcracks form on the surface and propagate deeper into the glass [1-3]. This leads to the degradation of the optical and mechanical properties of the glass windows of a spacecraft. One way to solve this problem is the deposition of refractory coatings with a high coefficient of elastic recovery and a low thermal coefficient of linear expansion transparent in the visible region of the spectrum [4,5]. Composite coatings consisting of metal and ceramic layers can have a wide range of properties.

In this paper the possibility of application of the magnetron deposition method of two-layer metal-ceramic coatings on the basis of $\mathrm{Ni} / \mathrm{Si}-\mathrm{Al}-\mathrm{N}$ to protect quartz glass from the high-velocity flow of hard microparticles used in the ports of a spacecraft is considered.

\section{EXPERIMENTAL PROCEDURE}

Plates of quartz glass of the KV type in the form of disks $15 \mathrm{~mm}$ in diameter and $4 \mathrm{~mm}$ in thickness were used as experimental samples. A two-layer coating was deposited on one side of the glass. The first metal layer was $50 \mathrm{~nm}$ in thickness and consisted of nickel (pure 99.99 wt.\%) It was deposited in the argon using a magnetron with unipolar pulsed power with a frequency of $50 \mathrm{kHz}$.

International Conference on Physical Mesomechanics of Multilevel Systems 2014

AIP Conf. Proc. 1623, 563-566 (2014); doi: 10.1063/1.4901499

(C) 2014 AIP Publishing LLC 978-0-7354-1260-6/ $\$ 30.00$ 
TABLE 1. Average values of the microhardness $H_{\mathrm{m}}$, the modulus of inelastic bucking $E^{*}$, the elastic recovery coefficient $k_{y}$

\begin{tabular}{lccc}
\hline \multicolumn{1}{c}{ Samples } & $\boldsymbol{H}_{\mathbf{m}}, \mathbf{G P A}$ & $\boldsymbol{E}^{*}, \mathbf{G P a}$ & $\boldsymbol{k}_{\mathbf{y}}$ \\
\hline Glasses without coatings & $9.26 \pm 0.58$ & $75.1 . \pm 3.8$ & $0.48 \pm 0.07$ \\
\hline Glasses with coatings Si-Al-N & $31.6 \pm 3.6$ & $264.7 \pm 19.5$ & $0.91 \pm 0.12$ \\
\hline
\end{tabular}

The second ceramic $8 \mu \mathrm{m}$ layer, consisting of silicon nitride-aluminum with the ratio of the atomic concentrations of $\mathrm{Si}: \mathrm{Al}=1: 4$, was deposited by magnetron reactive sputtering of composite targets using the vacuum unit UVN-05MI KVANT (NPP Tehimplant Ltd., Russia) [5]. The power was supplied from a magnetron pulse bipolar source with a frequency up to $100 \mathrm{kHz}$ and was stabilized (OOO “Applied Electronics", Russia).

The microstructure and the phase composition were investigated by transmission electron microscopy (TEM) a JEM-2100 instrument (Jeol, Japan). The average grain size $\langle d\rangle$ was determined using darkfield images obtained by TEM.

The phase and the chemical composition of individual structural components and the thin layers in the coating were determined using the modes of microdiffraction and the electron microprobe analysis by TEM. Foils for investigation were prepared by the "cross-section" method using an ION SLISER EM-09100IS device (Jeol, Japan).

The microhardness, the elasticity modulus and the elastic recovery coefficient of the coatings and the glass substrates were measured using NanoHardness Tester (CSM Instruments, Switzerland) under $20 \mathrm{mN}$ a load on the indenter (Table 1).

To test a sample for impact resistance, a special tooling was designed, which was a subject table placed in a vacuum chamber at a fixed position relative to the light-gas gun barrel. This table was designed for simultaneous deployment of four original glasses and four glasses with coatings in strictly defined positions relative to the lightgas gun barrel. Bombardment particles for the experimental samples were microparticles of iron selected with an average size of $56.3 \pm 8.2 \mu \mathrm{m}$, with a particle shape close to spherical. The portion of powder for each shot was constant $60.0 \pm 0.1 \mathrm{mg}$, the shot velocity was $3-5 \mathrm{~km} / \mathrm{s}$.

\section{RESULTS AND DISCUSSION}

It was established by TEM (Fig. 1) that the first metallic layer in the coating was nanocrystalline and monophase. There were nanograins with the fcc crystalline lattice (Fig. 1(e, f)). The second layer of Si-Al-N coating had a twophase nanostructure consisting of AlN crystallites with the hep lattice and the $\mathrm{Si}_{3} \mathrm{~N}_{4}$ phase in the amorphous state in the form of layers between the AlN grains. Using the dark-field images obtained by TEM, the average grain size of the AlN phase was determined, which was in the range of 5-10 nm.

The microstructure and the phase composition of the coatings differed from the coatings produced previously on the basis of $\mathrm{Si}-\mathrm{Al}-\mathrm{N}$ [6] due to the differences in the chemical composition and the mode of preparation. Their characteristics were closer to the coatings on the basis of Al-Si-N studied in [7].

The coefficient of light transmission is measured by the UVIKON 943 spectrophotometer (Kontron Instruments) in the visible area of wavelengths no less than $0.85 \pm 0.02$ and is close to the value for glass without a coating $(0.90 \pm 0.02)$.

The microhardness $\mathrm{Hm}$ was measured for the $\mathrm{Si}-\mathrm{Al}-\mathrm{N}$ silica glass with and without a coating, the elastic recovery factor $k_{\mathrm{y}}$ and the modulus of inelastic buckling $E^{*}$ were determined. These data are shown in Table 1 . It is seen that the microhardness of the samples with coatings is 3.4 times higher and the elastic recovery factor is 1.8 times greater compared with the samples without coatings. As for the modulus of inelastic buckling, its value for the samples with coatings is 3.5 times greater compared with the samples without coatings.

After shooting of the glasses by Fe microparticles a 10-20 nm thin silver film (a conductive layer) was deposited on their surface. Then the surface morphology of the samples was studied by SEM. Investigations were carried out in the secondary electron mode with the magnification 100 at an accelerating voltage of $20 \mathrm{kV}$. Each sample series of images was photographed and then joined together to produce a panorama. After that an area about $100 \mathrm{~mm}^{2}$ was chosen on each of the 8 samples and measurements of the transverse size were made. The results for all samples with coatings were tabulated and treated as a single array. These data were compared with similar data obtained for 4 samples of the original glass without coatings. Figure 2 shows an image obtained by SEM, where the circles outlined the craters appearing after shooting. It was established that the crater surface density of glasses with coatings is significantly lower than for the glasses without coatings at the same test conditions (Fig. 1). The surface density $\rho$ for the glasses with coating was $0.39 \times 10^{6} \mathrm{M}^{-2}$ and for the glasses without coatings was $1.08 \times 10^{6} \mathrm{M}^{-2}$. 


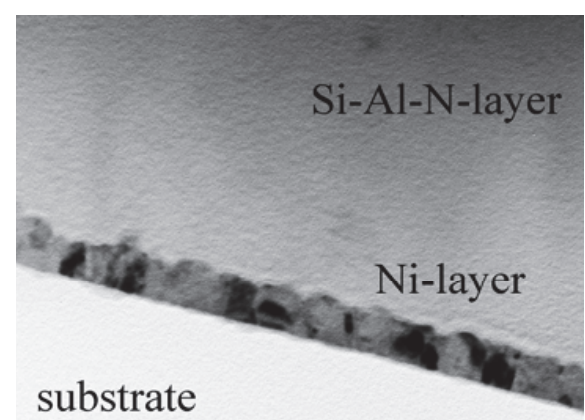

Magnification Stage Tilt $\mathrm{X}$-axis

$150000 \times \quad-0,15^{\circ} \quad-200 \mathrm{~nm}-$

(a)

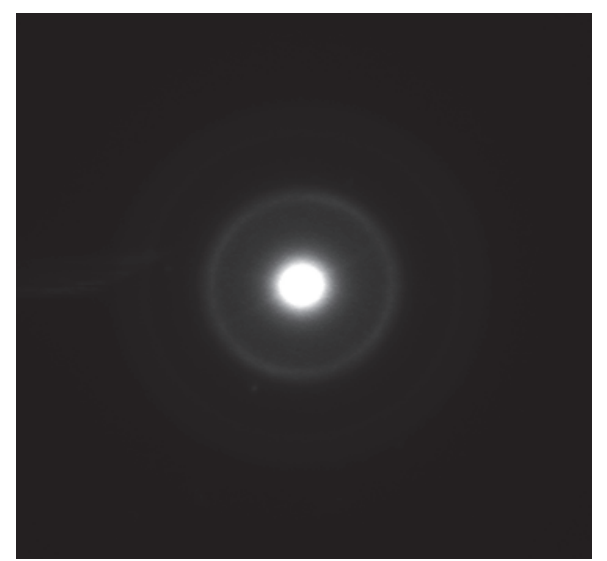

(b)

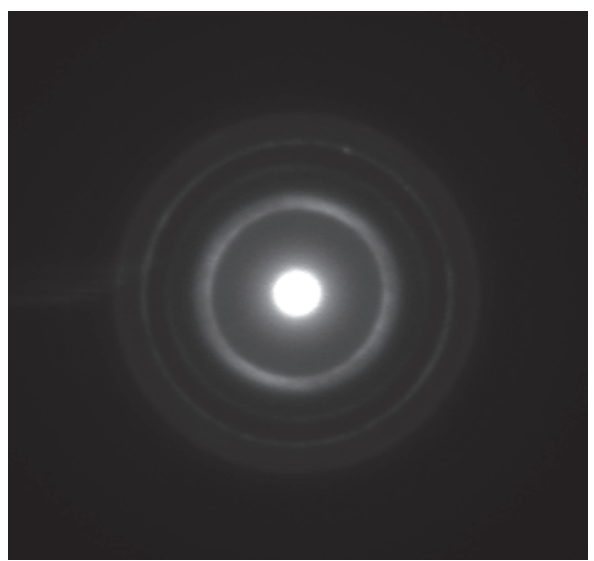

(c)

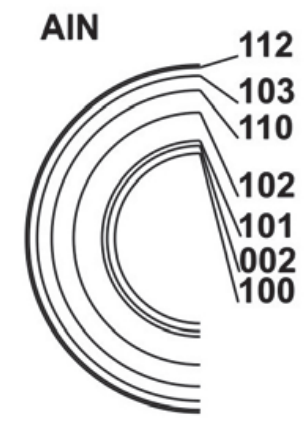

(d)

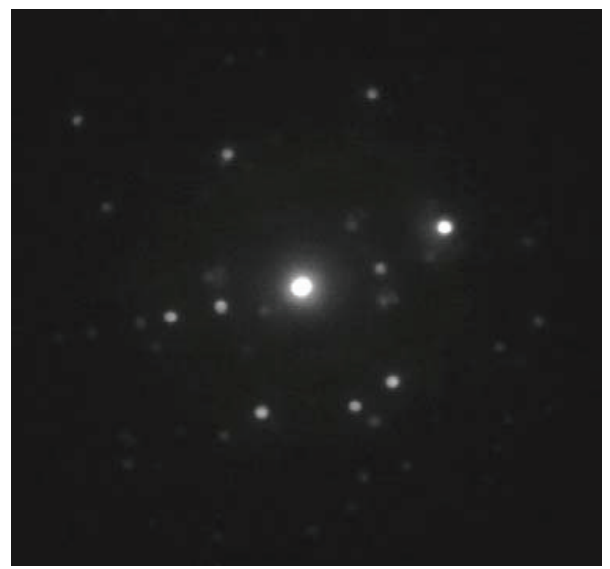

(e)

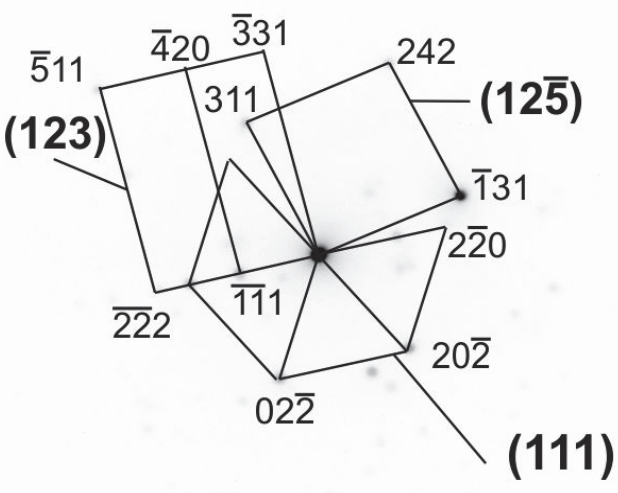

(f)

FIGURE 1. TEM image of the cross-section of the two-layer coating Ni/Si-Al-N: bright-field (a) microdiffraction pattern of the amorphous layer (b), microdiffraction pattern of the coating on the basis of $\mathrm{Si}-\mathrm{Al}-\mathrm{N}(\mathrm{c}, \mathrm{e})$ and schemes of their indexing $(d, f)$ 


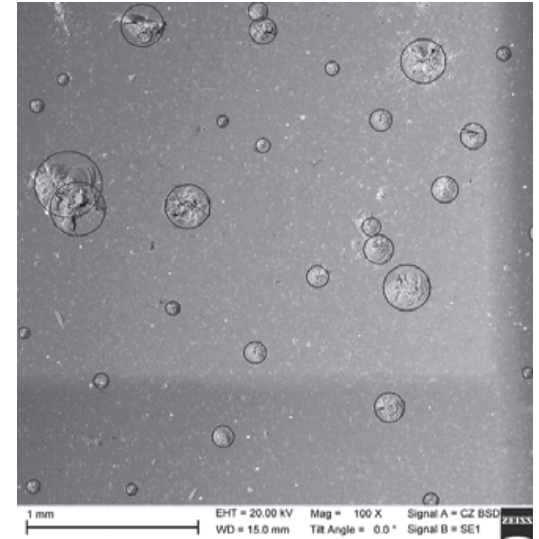

(a)

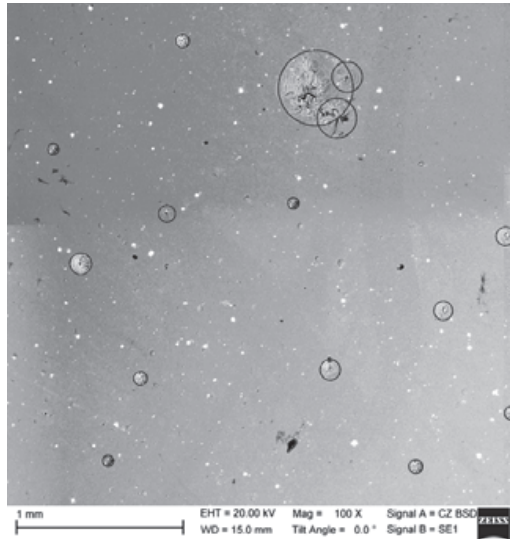

(b)

FIGURE 2. The images of craters formed under a flux of the iron particles on the samples without (a) and with coatings (b)

Thus, the deposition of two-layer metal-ceramic nanocomposite coatings decreases $\sim 2.7$ times surface density of the craters, formed on the surface of the silica microparticles during shooting by Fe microparticles moving at a velocity of $3-5 \mathrm{~km} / \mathrm{c}$.

\section{CONCLUSION}

In this work it is shown that the metallic-ceramic coatings on the basis of $\mathrm{Ni} / \mathrm{Si}-\mathrm{Al}-\mathrm{N}$ obtained by pulsed magnetron sputtering of composite targets have a two-layer nanostructure consisting of the Ni monophase nanograin layer $50 \mathrm{~nm}$ in thickness, crystallites of the AlN phase with the hcp crystalline lattice and the $\mathrm{Si}_{3} \mathrm{~N}_{4}$ phase having the amorphous structure in the form of layers between the grains of the AlN phase $8 \mu \mathrm{m}$ in thickness. The average grain size of AlN was in the range of 5-10 nm.

These coatings are transparent in the visible spectrum and they have high values of microhardness, the modulus of elasticity and the elastic recovery ratio. Their deposition on quartz glass increases the glass impact resistance to iron microparticles with an average size of about $56 \mu \mathrm{m}$ moving at a velocitiy of $3-5 \mathrm{~km} / \mathrm{c}$. The obtained data have shown that the deposition of coatings on the basis of $\mathrm{Si}-\mathrm{Al}-\mathrm{N}$ on quartz glass leads to the decrease in the surface density of the craters 2.7 times at the bombardment of the glass with light gas guns.

\section{ACKNOWLEDGEMENTS}

The work was supported within the scope of the basic scientific research of state academies of sciences for 2013-2020 performed within the scope of state task "Science NRTPU".

\section{REFERENCES}

1. E. M. Silverman, "Space Environmental Effects on Spacecraft: LEO Materials Selection Guide", NASA Contractor Report 4661, Part 1, 1995.

2. L. S. Novikov, Exposure to Particulate Matter of Natural and Artificial Origin on the Spacecraft (Moscow, 2009).

3. V. E. Panin, V. P. Sergeev, D. D. Moiseenko, and Yu. I. Pochivalov, Fiz. Mezomekh. 14(6), 5 (2011).

4. R. A. Andrievsky and I. I. Spivak, Silicon Nitride Materials on the Basis Thereof (Metallurgy, Moscow, 1984).

5. V V. P. Sergeev, V. P. Yanovsky, Yu. N. Paraev, S. A. Kozlov, and S. A. Zhuravlyov, Fiz. Mezomekh. 7(Spec. Iss.), 333 (2004).

6. V. P. Sergeev, M. V. Fedorishcheva, A. R. Sungatulin, A. V. Nikalin., and V. V. Neufeld, Proc. TPU 319(2), 103 (2011).

7. J. Musil, M. Šašek, P. Zeman, R. Čerstvý, D. Heřman, J. G. Han, and V. Šatava, Surf. Coat. Tech. 202, 3485 (2008). 